\title{
Policy Strategies and Paths to promote Sustainable Energy Systems - The dynamic Invert Simulation Tool
}

\author{
Michael Stadler, ${ }^{\mathrm{a}, \mathrm{b}}$, Lukas Kranzl ${ }^{\mathrm{a}}$, Claus Huber ${ }^{\mathrm{a}}$, Reinhard Haas ${ }^{\mathrm{a}}$ and Elena Tsioliaridou ${ }^{\mathrm{c}}$ \\ ${ }^{a}$ Energy Economics Group, Vienna University of Technology, \\ Gusshausstraße 25-29/373-2, 1040 Wien \\ Tel.: +43 1 58801/37361, Fax: +43158801/37397 \\ Email corresponding author: stadler@eeg.tuwien.ac.at \\ ${ }^{\mathrm{b}}$ Currently Lawrence Berkeley National Laboratory, 1 Cyclotron Road, \\ Berkeley, CA 94720, USA \\ ${ }^{c}$ Democritus University of Thrace, Department of Electrical and Computer Engineering, \\ Energy Economics Laboratory, 12 Vas. Sofias Str, 67100 Xanthi, Greece.
}

\begin{abstract}
The European Union has established a number of targets regarding energy efficiency, Renewable Energy Sources (RES) and $\mathrm{CO}_{2}$ reductions as the 'GREEN PAPER on Energy Efficiency', the Directive for 'promotion of the use of bio-fuels or other renewable fuels for transport' or 'Directive of the European Parliament of the Council on the promotion of cogeneration based on a useful heat demand in the internal energy market'. A lot of the according RES and RUE measures are not attractive for investors from an economic point of view. Therefore governments all over the world have to spend public money to promote these technologies/measures to bring them into market. These expenditures have to be adjusted to budget concerns and should be spent most efficiently. Therefore, the spent money has to be dedicated to technologies and efficiency measures with the best yield in $\mathrm{CO}_{2}$ reduction without wasting money.
\end{abstract}

The core question: "How can public money - for promoting sustainable energy systems - be spent most efficiently to reduce GHG-emissions?" has been well investigated by the European project Invert. In course of this project a simulation tool has been designed to answer this core question. This paper describes the modelling with the Invert simulation tool and shows the key features necessary for simulating the energy system. A definition of 'Promotion Scheme Efficiency' is given which allows estimating the most cost effective technologies and/or efficiency measures to reduce $\mathrm{CO}_{2}$ emissions. Investigations performed with the Invert simulation tool deliver an optimum portfolio mix of technologies and efficiency measures for each selected region. Within Invert seven European regions were simulated and for the Austrian case study the detailed portfolio mix is shown and political conclusions are derived.

Keywords: $\mathrm{CO}_{2}$ emissions, promotion schemes, policy strategies, DSM, RES-E, RES-CHP, district heating, biofuels, solar thermal systems, dynamic bottom-up modelling 


\section{Introduction}

National and international targets, commitments and guide lines are claiming an increase of renewable energy sources as well as higher efficiency in the energy usage and as a result a decrease in $\mathrm{CO}_{2}$ emissions.

However, all relevant political players are acting in a very sensitive area and feel the tension between environmental and political concerns:

- Environmental and energy policy goals may be in opposition

- The taxation of energy in particular of fossil energy is not very popular (even in those cases where it would be the most efficient tool as the simulation runs with Invert and other investigations indicate). Therefore, it seems necessary to use public money to promote sustainable energy systems via promotion schemes. This fact results to the third challenge

- The promotion of renewable energy has to be harmonised with the budget relevant goals of a government.

This reflections leads to the main question:

How can public money - for promoting sustainable energy systems - be spent most efficiently to reduce GHG emissions?

The European project Invert deals exactly with this question. The Altener project Invert "Investing in RES and RUE technologies: models for saving public money" was leaded by the Energy Economics Group and combined seven international research institutes as well as five international energy agencies.

Within this project the dynamic bottom-up Simulation Tool Invert was designed by the Energy Economics Group to answer the above question and evaluate the effects of different promotion schemes on the technology mix and the achievable $\mathrm{CO}_{2}$ reductions in the building, electricity and transport (bio-fuel) sector till 2020.

This paper describes the special features of the Invert Simulation Tool to answer the key question and demonstrates the political strategies and paths which can be derived from the simulation tool by showing the Austrian case study of the project Invert. 


\section{The dynamic Invert Simulation Tool}

\subsection{Introduction ${ }^{1}$}

Invert ${ }^{2}$ is a dynamic bottom-up simulation tool applicable on the existing building stock (for heating, cooling, domestic hot water systems (DHW) - including solar thermal systems, rational use of energy (RUE), as well as renewable energy sources according electricity supply (RES-E) and heat production (RES-CHP) and for bio-fuel production. Invert allows comparative and quantitative sensitivity analyses of the interactions between promotion schemes for RUE, RES-E, RES-CHP, and bio-fuels as well as corresponding greenhouse gas (GHG) -reduction for each selected region.

\subsection{Description of the model}

\subsubsection{Decision making process in Invert}

Invert models the decisions making process of the investors taking into account market restrictions (e.g. RES-E market barriers, learning curves, consumer behaviour). However, basically two different approaches - depending on the sector - are used in Invert.

For the building sector (including DSM, heating, cooling, DHW, solar thermal) an option ${ }^{3}$ approach is used. Within this approach the decision making process of various consumers and investors is modelled by comparing different options (e.g. heating systems). In contrast to the option approach in the RES-E, RES-CHP and bio-fuel sector a dynamic cost curve approach is used. These two different approaches are depicted in the following chapters.

\subsubsection{Decision making process in the building part of Invert (option approach)}

In the building sector for each old system (= expired lifetime) different new system options exist. The decision maker (e.g. house owner, renter) selects a new technology option on basis of the new system costs (a function of investment, operation and maintenance costs), the savings compared to the old system, the change in comfort and the promotion scheme support (e.g. investment subsidies). Now, the difficulty is to incorporate non monetary comfort issues in the model and generate realistic simulations of the decision process. These considerations result in a system which is using factors (=Soft Barriers) modifying the pure monetary costs

\footnotetext{
${ }^{1}$ For the simulations carried out for this paper, Invert was basically used to evaluate the effects of different promotion schemes (investment subsidies, feed-in tariffs, tax exemptions, subsidy on fuel input, $\mathrm{CO}_{2}$ taxes, soft loans, and additional aside premium) on the energy carrier mix, $\mathrm{CO}_{2}$ reductions and costs for society due to promoting certain strategies. Furthermore, different scenarios (price scenarios, insulation scenarios, different consumer behaviours, etc.) and the according impact on future trends of renewable as well as conventional energy sources were performed.

${ }^{2}$ The model can be downloaded from the project homepage www.Invert.at.

${ }^{3}$ A complete overview about considered technology options can be gathered from Kranzl et al 2004.
} 
and gains. Theses 'Soft barriers' are found by a calibration process comparing the real historical observed energy consumptions and the calculated monetary costs for each building type and investor group. The 'Soft barriers' get adjusted in a way that the historical observed energy consumption matches the calculated energy consumption.

Before the model starts to simulate the actual decision making process, the number of old systems (= expired lifetime) is determined. Invert uses a replacement rate on basis of the lifetime of the existing equipment. This means $1 /$ lifetime of a certain equipment specifies the number of equipment which can be replaced by a new option every year.

With these found 'Soft Barriers' and replacement rates impacts of different promotion schemes, energy prices and strategies can be simulated dynamically till $2020^{4}$.

The calculation of the 'option costs' is shown in Figure 2.1. Starting with the technology data (investment costs, lifetime, OM costs, and efficiency), the risk evaluation of the future (Individual Payback Time ${ }^{5}$ ) and the fuel costs as well as the average interest rate the yearly costs for all possible replacement options get calculated.

Yearly Costs for Options without Schemes (YC)
$=\mathrm{f}($ Technology , Investment costs, Lifetime, Payback Time,
OM costs, Fuel costs, Efficiency, Interest rate)

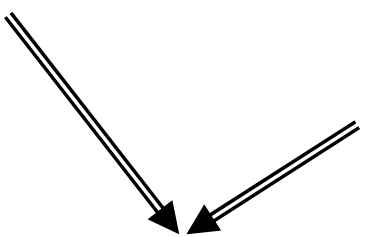

Promotion Schemes

(Investment Subsidies, Soft loans, Taxes)

Yearly Costs for Options with Schemes (YCS)

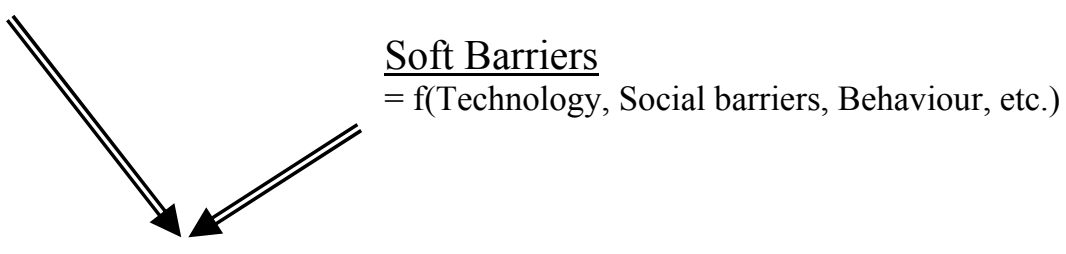

$\underline{\text { Final Option Costs }(\mathrm{FYCS})=(1+\text { Soft Barrier Factor }) \mathrm{xYCS}}$

Figure 2.1: Calculation of option costs in the building sector in Invert

\footnotetext{
${ }^{4}$ This approach assumes that the 'Soft Barrier' factors are constant over time and the decision makers do not learn over time. This assumption will be removed in future versions of the model.

${ }^{5}$ The calculation of the Capital Recovery Factor is either based on the lifetime or individual payback time. The user of the model is able to select between 'Individual Payback Time' and 'Lifetime' of the equipment as basis for the simulation of the investors' decision making process within the building part of Invert. If the user selects the 'Individual Payback Time' the tool considers all costs and benefits (e.g. due to solar thermal systems and 'Insulation' as well as 'Windows') for the individual 'Payback Time'. With this approach Invert is able to calculate the maximum yearly costs seen by the consumer. Exactly these costs are the important decision making parameters for the so called Landlord problem. However, this approach corresponds with a risk evaluation of the future. For more information please see Stadler et al 2004.
} 
Having calculated all option costs and using no promotion schemes as well as soft barriers the option costs are represented by YC. The cheapest option in each consumer group (= building class in Figure 2.2) will be used. This means for the example in Figure 2.2 for the building class 1 option 4 and for building class 2 also option 4 will be considered.

However, without promotion schemes almost no renewable energy sources or RUE measures may be applied because of high yearly option costs compared to conventional energy systems and therefore it could be necessary to use promotion schemes. The yearly costs considering promotion schemes are represented by the dashed bars YCS in the example below. Because of the used promotion schemes different options - compared to before - are the cheapest now (see Figure 2.2: building class 1: option 3 and for building class 2: option 1).

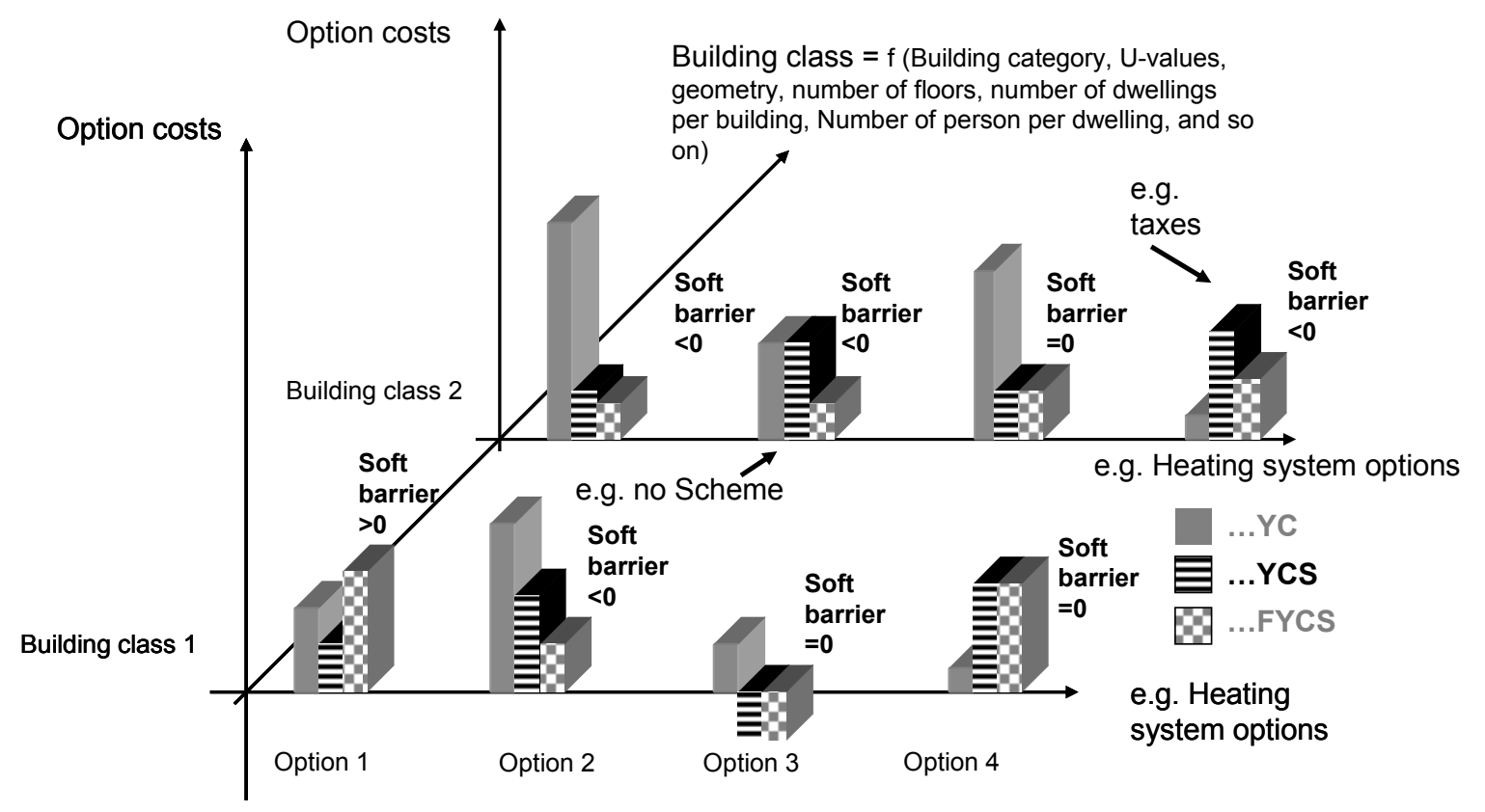

Figure 2.2: Option based approach in the building sector in Invert. Example: Heating options

However, the last step is to consider all other technical ${ }^{6}$ and non technical barriers ${ }^{7}$ or incentives via the 'Soft Barriers'. As already pointed out the decision making process of the consumer is influenced by a variety of different technical and non technical aspects (e.g. comfort, social barriers, education).

Other models apply the concept of varying interest rate for modelling the impact of consumer preferences. However, the methodology of applying soft barriers only partially refers to the type of consumer preference modelling in this paper. Rather the concept applied in this paper refers to very technology specific issues, especially of heating systems and corresponding

\footnotetext{
${ }^{6}$ E.g. missing district heating grid, in urban regions the problem of wood storage for wood heating systems, etc.

${ }^{7}$ E.g. comfort, social pressure, education, beliefs, willingness to pay, etc.
} 
comfort aspects. Actually, different types of heating systems cannot be regarded as homogenous goods for providing space heating. E.g. single stoves in general are considered to be less comfortable than central heating systems. Furthermore, some authors use the concept of required time for the operation of heating systems. Again, this approach requires assigning a monetary value for the leisure time of people which again raises methodological problems.

Therefore, Invert uses 'Soft Barriers' according Figure 2.1 to adapt the monetary yearly costs (YCS) to get the 'Final Option Costs' (FYCS) as the relevant decision criteria seen by the consumer (dotted bars in Figure 2.2). The Soft barriers have to be higher than minus 1. A soft barrier of zero means that the consumer recognizes exactly the monetary costs (YCS). A soft barrier $>0$ means that for this certain technology technical or social barriers exist and therefore the investor recognizes a lower comfort or higher anticipated option costs.

Of course, the calibration of the soft barriers is on of the crucial steps within the simulation tool. This process is done by the use of historical empirical data for the actual penetration of various technologies. The results of the model are calibrated to these data. It gives the user the possibility to estimate a socio-economical interface between the investor and technology and allows simulating the Rebound Effect which considers a rebound in energy consumption due to higher comfort levels after heating system upgrades (see also Haas et al 1997).

Table 1: Some 'Soft Barriers' for heating options derived from the Austrian case study

\begin{tabular}{|c|c|c|c|}
\hline \multirow{2}{*}{ Building category } & \multicolumn{3}{|c|}{ Soft barrier } \\
\hline & wood single & oil single & electricity single \\
\hline Single dwelling (ch, dh) & 0.3 & 0.2 & 0 \\
\hline Multiple dwelling (ch, dh) & 0.4 & 0.3 & 0 \\
\hline Single dwelling (no ch, dh) & 0.3 & 0.2 & 0 \\
\hline Multiple dwelling (ss, dh) & 0.4 & 0.3 & 0 \\
\hline Multiple dwelling (of, dh) & 0.4 & 0.3 & 0 \\
\hline Single dwelling (ch, no dh) & 0.3 & 0.2 & 0 \\
\hline Multiple dwelling (ch, no dh) & 0.4 & 0.3 & 0 \\
\hline Single dwelling (no ch, no dh) & 0.3 & 0.2 & 0 \\
\hline Multiple dwelling (ss, no dh) & 0.4 & 0.3 & 0 \\
\hline Multiple dwelling (of, no dh) & 0.4 & 0.3 & $\underline{0}$ \\
\hline $\begin{array}{l}\text { combined hea } \\
\text { district heatin } \\
\text { no available d } \\
\text { one floor heat }\end{array}$ & $\begin{array}{l}\text { connection is } \\
\text { strict heating } \\
\text { ng system; ss }\end{array}$ & $\begin{array}{l}\text { ing plus D } \\
\text { principle } \\
\text { nection } \\
\quad \text { single }\end{array}$ & $\begin{array}{l}\text { W) } \\
\text { ssible }\end{array}$ \\
\hline
\end{tabular}

Table 1 shows representative some soft barriers derived from the Austrian case study. The low comfort for wood and oil single systems results to positive soft barrier values of 0.4 to 0.2 . In contrast to the wood and oil single systems electricity single is very easy to install and handle and therefore the soft barrier factor results to zero in the Austrian case. 
2.2.3 Decision making process in the RES-E/CHP and bio-fuel part of Invert (cost resource curve approach)

For the simulation of the electricity (RES-E), grid connected heat (RES-CHP) and bio-fuel sector a dynamic cost resource curve approach is used. The different technologies are represented by so called 'bands' and sorted in a least cost order. Each band summarizes technologies with a similar characteristic like possible application, size, efficiency, generation costs, availability, and so on.

In the RES-E, RES-CHP and bio-fuel part of Invert for each 'band' the potentials and costs (short term costs for already existing plants and long term marginal costs for possible future plants) for the electricity/heat as well as bio-fuel production are gathered and sorted in a least cost order. Each 'band' is described by a certain set of parameters.

For example wind: All wind farms/plants with the same full loud hour can be gathered and treated as one unique 'band'. Of course, in reality a continuous cost curve exists. However, for the modelling in Invert we use stepped discrete functions as an approximation. Furthermore, up to now this would neglect the influence of time and learning effects. Therefore, the simulation tool considers also the effects of learning curves and market barriers which lead to the concept of dynamic cost resources curves. These are applied in the simulation tool Invert.

The market barriers reduce the potential and the learning curves reduce the costs of the static cost resource curve as indicated by the 'Dynamic cost resource curve for a certain year' in Figure 2.3.

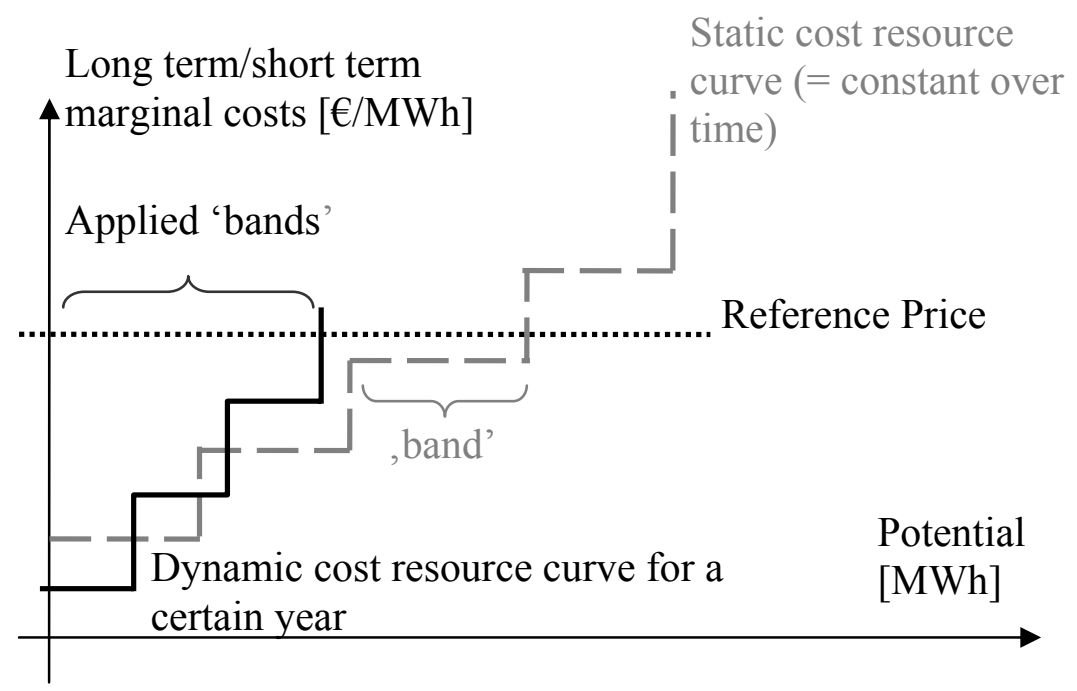

Figure 2.3: Cost resource curve approach used in the RES-E, RES-CHP and bio-fuel part of Invert ${ }^{8}$

\footnotetext{
${ }^{8}$ See also www.Green-X.at and the Green-X simulation tool.
} 
In contrast to the option based approach of the building sector in the RES-E/CHP and bio-fuel part no replacement rate is used. It is assumed that all RES-E/CHP or bio-fuel bands get installed or used when the costs (dynamic cost resource curve) for the electricity/heat or biofuel production is lower than the electricity or bio-fuel reference price as indicated in Figure 2.3 (for further details according costs curves see Resch et al 2004 and Ragwitz et al 2003).

2.2.4 Brief description of the implemented promotion schemes

All currently ${ }^{9}$ in Invert implemented promotion schemes are shown in Table 2 and Table 3.

At the electricity part the promotion schemes are separated to RES-E and RES-CHP. Invert considers in this part only promotion schemes for renewables. Promotion schemes for conventional energy carriers can be considered only in the building part (heating, cooling, DHW).

The two major promotion schemes in the building sector (investment subsidy and soft loans) can be applied on each defined (by the user) building category (e.g. single family dwelling, multifamily dwelling) and defined technology for heating, cooling, DHW, solar thermal systems. Furthermore, it is possible to assign a certain Demand-Side (DS) strategy for each defined building category and building part (walls, ceiling, floor, and windows).

Table 2: Currently in Invert implemented Promotion Schemes, part one

\begin{tabular}{|c|c|c|c|c|c|}
\hline Sector & Sub sector & $\begin{array}{c}\mathrm{CO}_{2} \\
\operatorname{tax}\end{array}$ & $\begin{array}{c}\text { Invest- } \\
\text { ment } \\
\text { subsidy }\end{array}$ & $\begin{array}{l}\text { Soft } \\
\text { Loan }\end{array}$ & $\begin{array}{c}\text { Feed in } \\
\text { tariff }\end{array}$ \\
\hline \multirow{5}{*}{ Building } & Heating & $\sqrt{ }$ & $\sqrt{ }$ & $\sqrt{ }$ & \\
\hline & $\begin{array}{c}\text { DHW } \\
\text { (including } \\
\text { solar } \\
\text { thermal) }\end{array}$ & $\sqrt{ }$ & $\sqrt{ }$ & $\sqrt{ }$ & \\
\hline & Cooling & $\sqrt{ }$ & $\sqrt{ }$ & $\sqrt{ }$ & \\
\hline & DSM & & $\sqrt{ }$ & $\sqrt{ }$ & \\
\hline & $\begin{array}{l}\text { District } \\
\text { heating }\end{array}$ & $\sqrt{ }$ & $\sqrt{ }$ & $\sqrt{ }$ & \\
\hline \multirow{3}{*}{ Electricity } & RES-E ${ }^{10}$ & $\sqrt{ }$ & $\sqrt{ }$ & & $\sqrt{ }$ \\
\hline & $\begin{array}{l}\text { RES- } \\
\text { CHP }^{11}\end{array}$ & $\sqrt{ }$ & $\sqrt{ }$ & & $\sqrt{ }$ \\
\hline & $\begin{array}{l}\text { District } \\
\text { heating }\end{array}$ & $\sqrt{ }$ & $\sqrt{ }$ & & $\sqrt{ }$ \\
\hline Bio-fuel & Bio-fuels & $\sqrt{ }$ & & & \\
\hline
\end{tabular}

\footnotetext{
${ }^{9}$ April 2005.

${ }^{10}$ Renewable Energy Source - Electricity

${ }^{11}$ Renewable Energy Source - Combined Heat and Power
} 
Table 3: Currently in Invert implemented Promotion Schemes, part two ${ }^{12}$

\begin{tabular}{|c|c|c|c|c|}
\hline \multirow{5}{*}{ Sector } & $\begin{array}{c}\text { Sub } \\
\text { sector }\end{array}$ & $\begin{array}{c}\text { Tax } \\
\text { exemption }\end{array}$ & $\begin{array}{c}\text { Subsidy } \\
\text { on fuel } \\
\text { input }\end{array}$ & $\begin{array}{c}\text { Additional } \\
\text { aside } \\
\text { premium }\end{array}$ \\
\hline \multirow{3}{*}{ Electricity } & RES-E & $\sqrt{ }$ & $\sqrt{ }$ & \\
\cline { 2 - 5 } & $\begin{array}{c}\text { RES- } \\
\text { CHP }\end{array}$ & $\sqrt{ }$ & $\sqrt{ }$ & \\
\cline { 2 - 5 } & $\begin{array}{c}\text { District } \\
\text { Heating }\end{array}$ & $\sqrt{ }$ & $\sqrt{ }$ & \\
\hline Bio-fuel & Bio-fuel & $\sqrt{ }$ & & $\sqrt{ }$ \\
\hline
\end{tabular}

\section{Efficiency Estimation of the Spent Public Money}

The basic idea for designing Invert is to estimate the efficiency of various promotion schemes and strategies to reduce $\mathrm{CO}_{2}$ emissions in the different sectors as building, electricity and transport.

In this context a 'Promotion Scheme Efficiency' (PSE) was defined to investigate the described issue.

$$
P S E=\frac{\sum_{i=1}^{n} \Delta \mathrm{CO}_{2} \text { Emissions }_{i}}{\sum_{i=1}^{n} \Delta \text { DiscountedTransferCosts }_{i}}
$$

$\triangle \mathrm{CO}_{2}$ Emissions $_{i} \quad$ Change in $\mathrm{CO}_{2}$ emissions compared to the reference scenario [kton/yr]

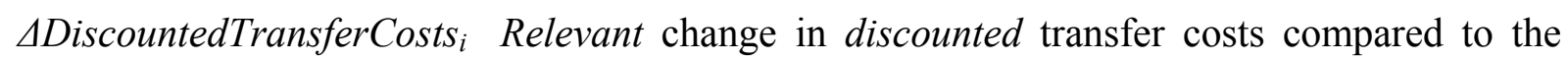
reference scenario [Mio $€ / \mathrm{yr}$ ]. Why Relevant Change? Let us assume a simulation period till 2020. In case of investment subsidies and use of a new measure in 2019 the entire costs get considered, but the $\mathrm{CO}_{2}$ reductions get only considered for two years (2019 and 2020). This circumstance results in an underestimation of the 'Promotion Scheme Efficiency'. Due to this circumstance only the relevant (2019 and 2020) discounted transfer costs are counted for the PSE.

$n$ Number of simulation years

The PSE estimates the efficiency of a certain strategy compared to a Business As Usual (BAU) scenario by comparing the $\mathrm{CO}_{2}$ emissions and necessary public transfer costs $(\approx$

\footnotetext{
${ }^{12}$ A detailed description of Policy Strategies and Promotion Schemes in the European countries gives Joergensen et al 2004.

${ }^{13}$ Note, in the Invert Simulation Tool two different promotion scheme efficiency indicators are used. These two values (CPSE/LPSE) indicate the second best promotion schemes by negative values. However, in this paper we use the negative LPSE value and term it PSE. Negative CPSE/LPSE values indicate a $\mathrm{CO}_{2}$ reduction accompanied with increased spent public money compared to the reference scenario. Therefore, the second best promotion schemes are identified by negative CPSE/LPSE $(=+$ PSE) values. Please see also Stadler et al 2004 and Stadler et al 2005.
} 
society costs for promoting a certain technology) of the BAU (= reference) scenario with the $\mathrm{CO}_{2}$ emissions and necessary public transfer costs of the sensitivity scenario.

Efficient promotion schemes (second best solution) are indicated by high decreases in $\mathrm{CO}_{2}$ emissions and low increases of transfer costs compared to the BAU scenario. However, the most efficient schemes (best solution) are those reducing both $\mathrm{CO}_{2}$ emissions and public transfer costs, which can be achieved by abolishing promotion schemes for conventional energy systems.

When it comes to the comparison of different promotion schemes the PSE is only one important dimension for the evaluation of the most efficient promotion scheme to reduce $\mathrm{CO}_{2}$ emissions. The PSE indicates how efficient money is spent to reduce $\mathrm{CO}_{2}$ emissions but does not reveal anything about the achievable entire $\mathrm{CO}_{2}$ reduction. Therefore, it is also necessary to consider the total $\mathrm{CO}_{2}$ reduction that can be achieved by a certain scheme. This second dimension is depicted in the Efficiency $-\mathrm{CO}_{2}$ graphs as shown in Figure 3.1

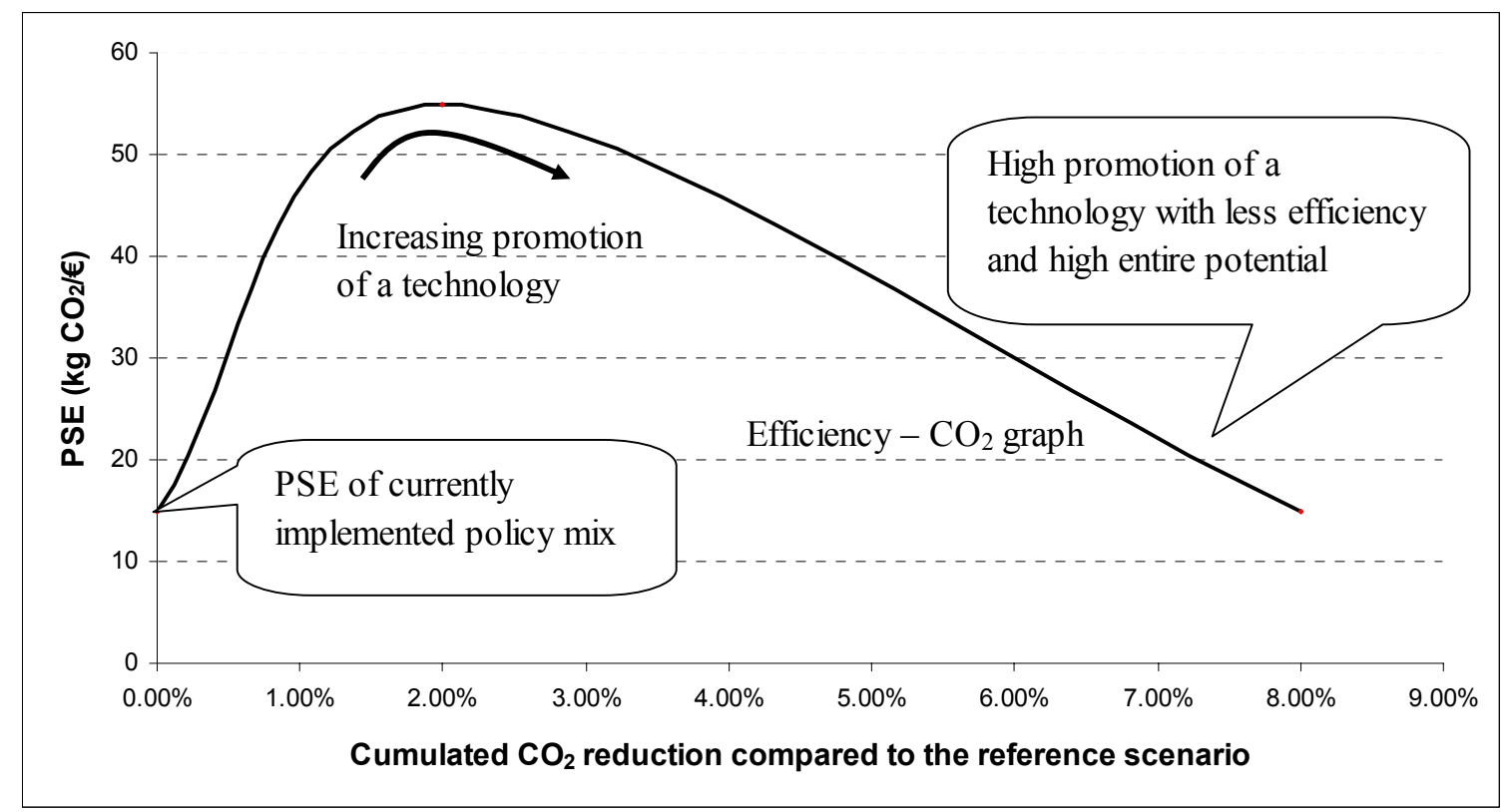

Figure 3.1: Example for an Efficiency- $\mathrm{CO}_{2}$ graph

The typical Efficiency $-\mathrm{CO}_{2}$ graph has a decreasing PSE as shown in Figure 3.1. In the figure above only one promotion scheme (e.g. investment subsidy for district heating) is varied during fixing all other possible promotion schemes. Doing so for each possible promotion scheme a set of different Efficiency $-\mathrm{CO}_{2}$ curve shapes and maximums come into being.

However, very important is that almost all efficiency curves have the same shape as illustrated in the figure above. Furthermore, the best area is indicated by reductions of $\mathrm{CO}_{2}$ emissions and negative PSE (i.e. negative costs, e.g. by abolishing subsidies for conventional energy systems, see Figure 3.2). The second best area (area right top in Figure 3.2) is indicated by a 
high efficiency and high $\mathrm{CO}_{2}$ reduction potential. The usual efficiency curve shape is always between the second best and the less efficient area, see Figure 3.2.

The question of a PSE maximum in the shape depends on the already implemented level of promotion schemes and efficiency of energy usage. E.g. if the existing building stock is distinguished by a high insulation quality all new additional demand-side measures result in decreasing efficiency values because of the exiting high quality. Hence countries (or regions) with a high level of building quality have to spend more money 'inefficiently' to reduce one $\mathrm{kg} \mathrm{CO}$ compared to countries with low efficiencies in the energy chain.

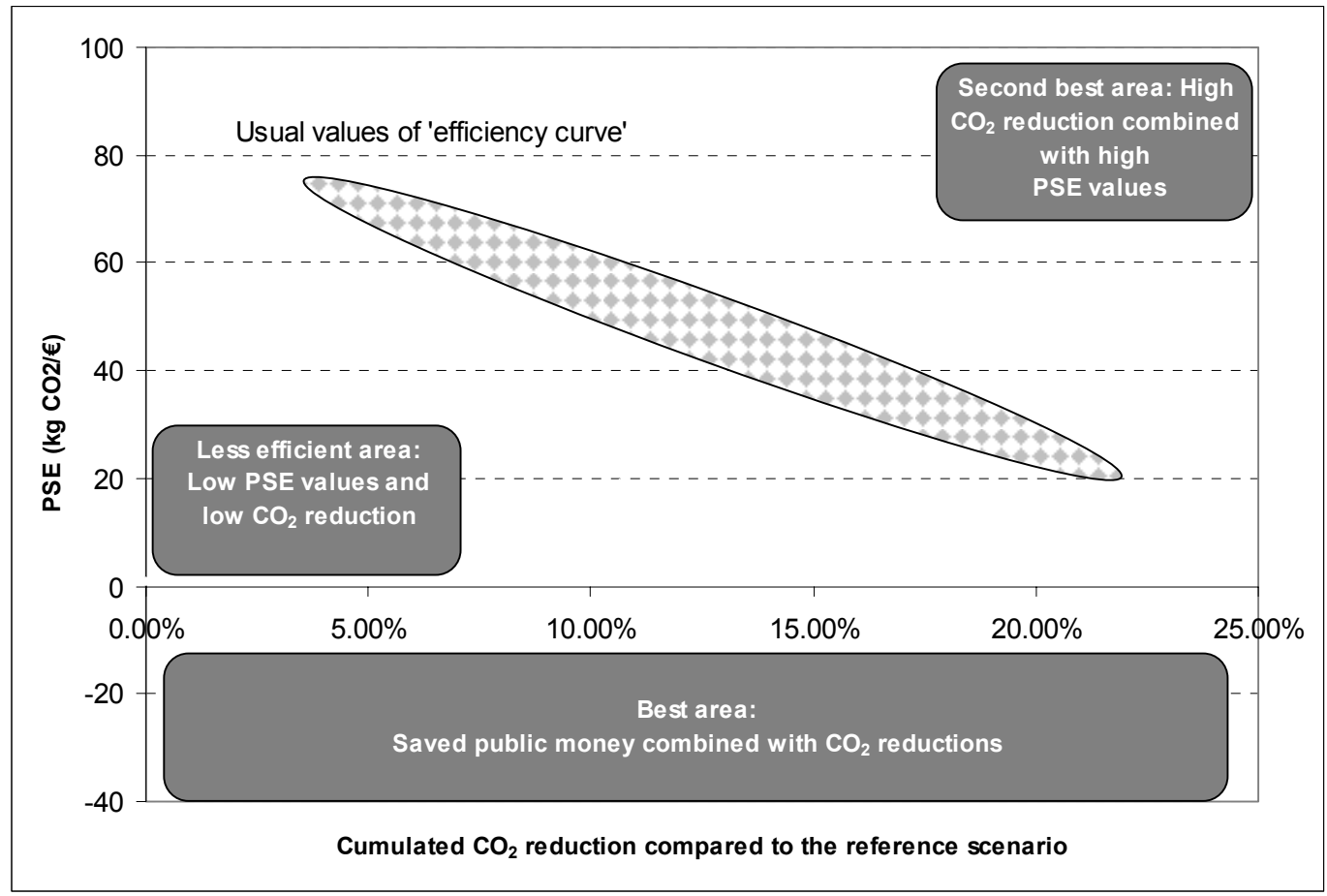

Figure 3.2: Identification of best and worst area for promoting RES and RUE technologies

A more detailed discussion is made in chapter Political conclusions derived from the Austrian case study - Synopsis.

\section{Political conclusions derived from the Austrian case study}

\subsection{Introduction}

In course of the project Invert seven different regions (case studies) were investigated:

- Vienna

- The province of Baden Würtemberg in Germany

- The small city of Jordanow in Poland

- The island of Crete

- Denmark

- Cornwall in UK and

- A solar thermal case in France 
For the Austrian case study different hypotheses for the heating of buildings (heat supply as well as RUE measures) according the promotion scheme efficiency compared to a reference scenario (=Business As Usual Scenario) were performed.

\subsection{Basic data for the Vienna heating sector}

The building stock in Vienna covers around 0.8 Mio dwellings. Due to the very urban characteristic, more than $90 \%$ of them are multiple dwellings. $42 \%$ of the dwellings have central heating systems, $34 \%$ heating systems covering one floor. Still there is a share of $23 \%$ of all dwellings providing heating with single stoves. However, these systems have been strongly declining in the past two decades.

Gas and district heating are strongly dominating the energy mix for heating in Vienna. Around $58 \%$ of the total energy consumption for heating is provided by natural gas, more than a quarter by district heating.

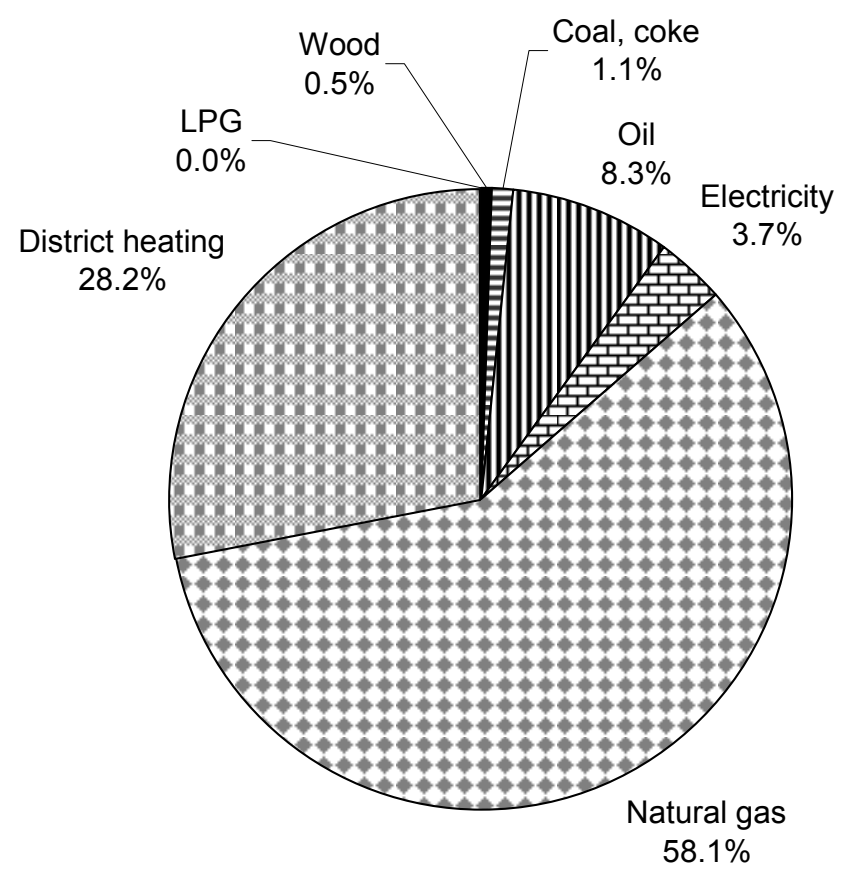

Figure 4.1: Share of energy carriers on the final energy consumption for heating

\subsubsection{Promotion schemes in Vienna}

A number of national energy policies have an impact on the situation in Vienna. The most important ones for the heating sector are ${ }^{14}$ Energy taxes (e.g. for heating oil, natural gas, electricity, transport fuels).

\footnotetext{
${ }^{14}$ The whole list of promotion schemes including RES-E and RES-CHP can be gathered from Ragwitz et al 2005.
} 
On a regional level the municipality of Vienna has adopted a number of energy promotion schemes targeting at the reduction of energy demand, the promotion of low-carbon technologies and renewable technologies. The most important ones are:

- Thewosan: This program targets on the improvement of building quality. Depending on the level of building quality which is achieved after refurbishment of the buildings and the amount of energy demand reduction, $30 € / \mathrm{m}^{2}, 45 € / \mathrm{m}^{2}, 60 € / \mathrm{m}^{2}$ or $75 € / \mathrm{m}^{2}$ are granted.

- Subsidy for biomass heating systems: According to the emission factors grants are given between 20 and $30 \%$ of the eligible investment costs. Moreover, costs for maintenance of boilers during the first two years are granted.

- Subsidies for solar thermal systems (30\% for DHW systems; $40 \%$ for combined systems space heating and DHW).

- Soft loans for window replacement (U-value lower than 1.9, no PVC windows).

- Support for installation of central heating systems and heating systems covering one floor.

- Subsidy for gas-condensing boilers.

- Support for low-energy buildings; requirement of energy efficiency standards for receiving general building construction subsidies.

- Subsidies for connection to district heating.

- Eco-electricity subsidy: Grants are given to PV systems up to $40 \%$ of the investment costs.

\subsubsection{The Vienna reference scenario: Assumptions and results}

The Reference Scenario is defined to represent the 'business as usual' development based on the existing promotion schemes. The main assumptions are:

- Moderate rise of fossil energy prices by approximately $1 \%$ per year (based on WIFObaseline scenario Austria see also Kratena (2001)).

- Wood price moderate rise of about $0.2 \%$ per year.

- Soft barriers for comfort (e.g. wood, coal single stoves), change of heat distribution system from single stove to heating system covering one floor respectively central heating; additional building requirement (e.g. storage availability for wood chips); (especially the soft barriers for central heating systems for the building categories with existing single stoves and heating systems covering one floor turned out to be essential. Moreover, biomass heating has proofed to be not very popular in Vienna and hence has a higher soft 
barrier. This goes in line with corresponding results of investigations about barriers for biomass heating systems in urban areas. ),

- Current support schemes are kept constant until 2020 on the current level.

From these assumptions we can gain the main simulation results characterizing the reference scenario. The development of the energy carrier mix is presented in Figure 4.2.

- The figure shows a moderate growth of district heating. This is due to the promotion schemes granted for connecting to district heating and for corresponding building construction requirements. Since a large part of the energy price paid for district heating consists of a flat rate, rising energy prices (only variably part) affect less the total costs for district heating to the consumers. A high share of the heating energy in Vienna's district heating grid comes from waste incineration and CHP. This supports the theses that the assumed moderate energy price increase of fossil fuels will affect the price of district heating less than oil and gas.

- Moderate growth of natural gas in the beginning of the simulation period, afterwards slight decrease. In the beginning of the simulation period, natural gas in most building types is the least cost heating option. However, due to rising energy prices these changes in the second part of the simulation period.

- All other energy carriers decrease (especially oil, electricity, coal). This reflects the development in the past decade.

- Single stove switch mainly to systems covering one floor. This is mainly due to comfort requirements. The corresponding soft barriers were calibrated by historical empirical data and therefore this development reflects the development in the past decade.

- Wood chips get economic attractive in the last 5 years of the simulation period. This development is mainly due to the smaller energy price increase of biomass compared to fossil fuels. Moreover, currently the municipality of Vienna has implemented promotion schemes for biomass. However, due to high barriers and high investment costs, these have almost no impact until the year 2015 .

- The share of solar thermal systems for domestic hot water is neglectable for the whole simulation period. It turns out that the rise of energy prices (1\% per year) and the current investment subsidies for solar domestic hot water systems (30\%) are not enough to provide a considerable incentive for these systems until the year 2020. 


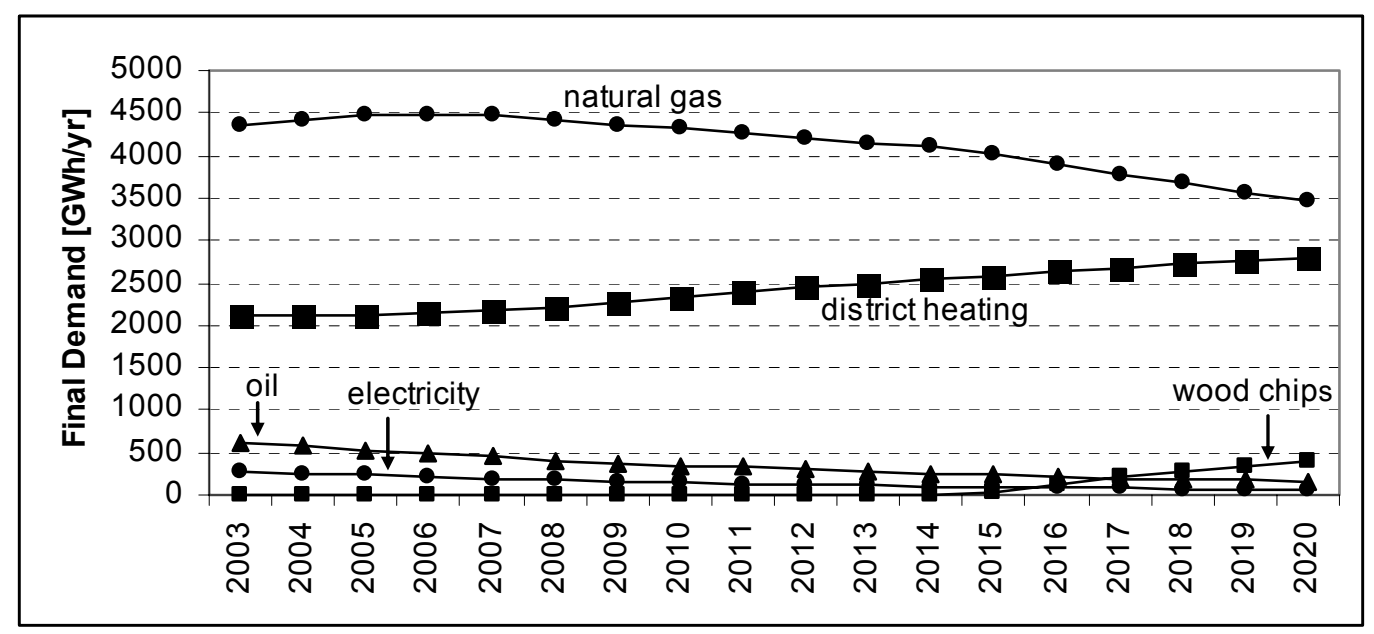

Figure 4.2: Energy carriers for heating, reference scenario Vienna

Figure 4.3 shows that in the reference scenario single stoves and heating systems covering one floor are increasingly replaced by central heating systems. Gas condensing systems increase especially in the first decade. In the second decade, their number stays stable. This is because the rising energy price is only partly compensated by subsidies for gas condensing boilers, currently granted by the municipality of Vienna.

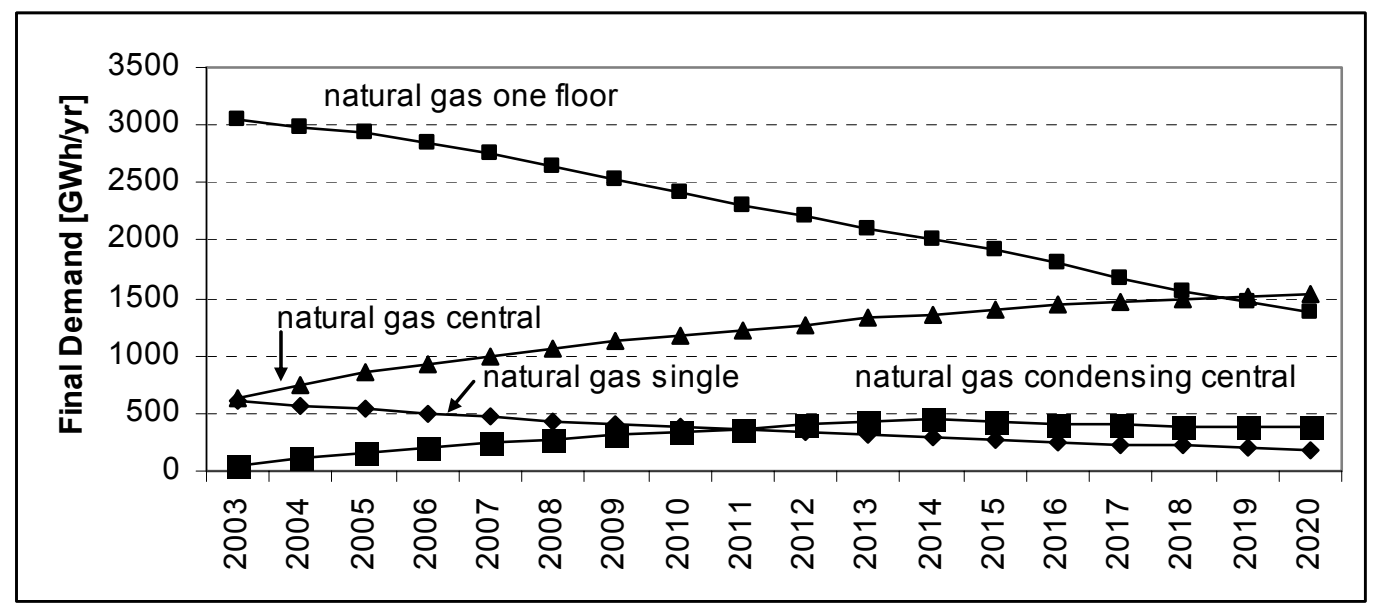

Figure 4.3: Development of gas heating technologies, reference scenario Vienna

The number of buildings refurbished is relatively low over the whole period. Building quality is increased for 5000 to 10000 dwellings per year. This leads to a reduction of total useful energy by about $10 \%$ until 2020 . However, due to the change of single stoves to central heating systems, service factors increase. This is a typical case of a rebound effect which leads to a partly compensation of energy reductions. Hence, the final energy demand only decreases by about $7 \%$.

Reduction of $\mathrm{CO}_{2}$ emissions due to insulation and window replacement amounts to around 190 kton- $\mathrm{CO}_{2}$ per year in 2020 . 


\subsubsection{Comparison of various measures for further $\mathrm{CO}_{2}$ reductions}

For achieving higher $\mathrm{CO}_{2}$ reductions than in the reference scenario various different measures are possible. In the following, some of them are compared to each other:

\section{- Raising subsidy for insulation and window replacement:}

The current promotion scheme for insulation and window replacement in Vienna is a subsidy where the level depends on the achieved energy savings. The subsidies are granted in Euro per living area of the concerning buildings.

Increasing this subsidy for insulation by $10 € / \mathrm{m}^{2}$ leads to a $\mathrm{CO}_{2}$ reduction potential of about 900kton (cumulated) until 2020. The amount of dwellings getting insulated doubles compared to the reference scenario.

The following Figure 4.4 shows the development of $\mathrm{CO}_{2}$ emissions in various scenarios of different levels of DSM subsidy (building insulation and window replacement) compared to the reference scenario.

In a maximum DSM Scenario $\mathrm{CO}_{2}$ emissions could be reduced by 4Mton (cumulated 2020). For this scenario it was assumed that all buildings getting refurbished replace their windows and insulate walls, ceiling and floor. It turns out that in the $+10 € / \mathrm{m}^{2}$ subsidy scenario around $22 \%$ of this potential would be achieved.

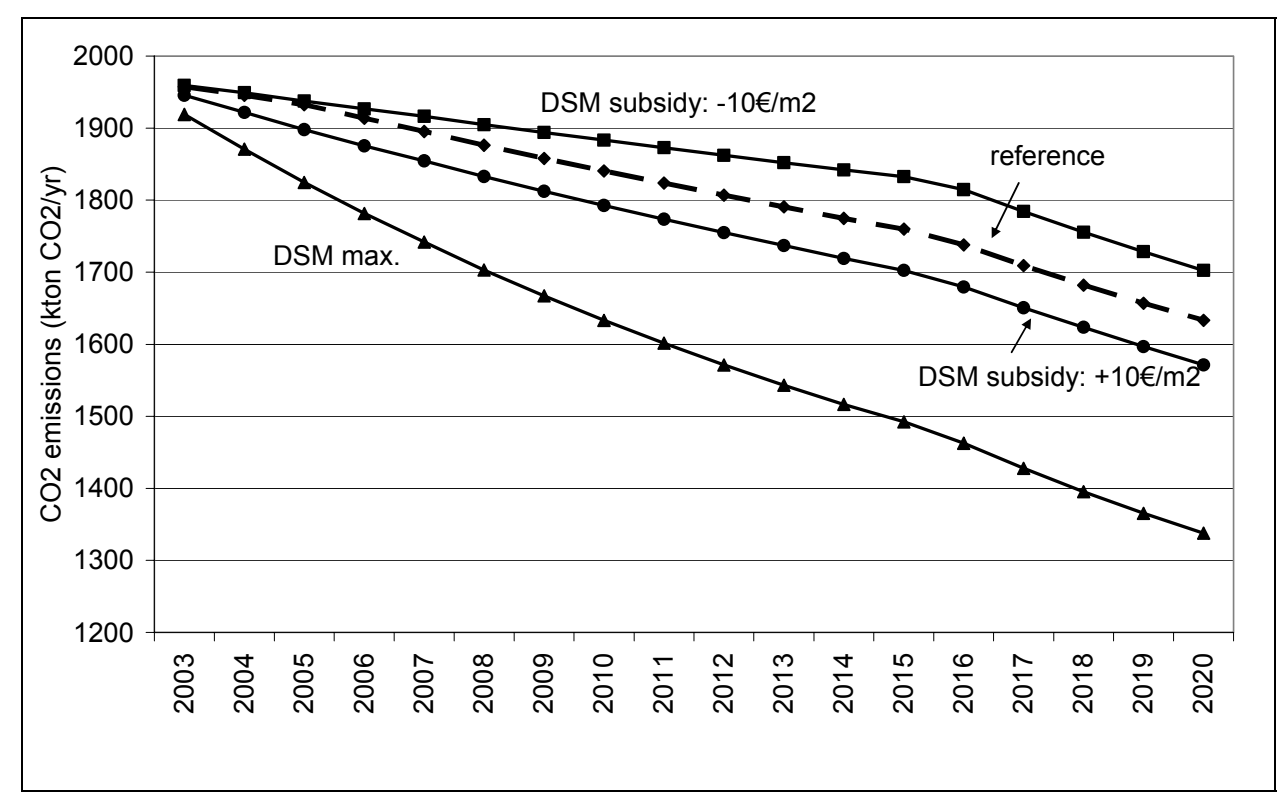

Figure 4.4: Development of $\mathrm{CO}_{2}$ emissions (heating and domestic hot water, Vienna) in various scenarios

The promotion scheme efficiency of increasing DSM subsidy by $10 € / \mathrm{m}^{2} \mathrm{is} 3.8 \mathrm{~kg} / €$. Compared to other options (see below) it turns out that the $\mathrm{CO}_{2}$ reduction potential of this measure is quite high and the promotion scheme efficiency relatively low. 


\section{- Raising subsidy for connection to district heating:}

In Vienna, there are subsidies for connecting to district heating and corresponding building

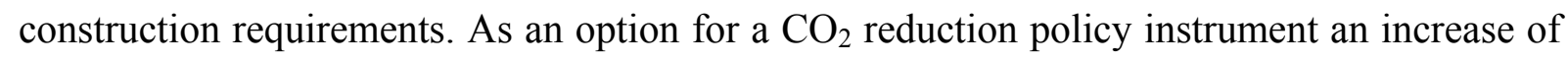
this subsidy was investigated in this paper. We could see that even in the reference scenario, with constant levels of district heating subsidy, there was a slight increase of district heating, in particular in the second part o the simulation period.

It turns out that by increasing the level of investment subsidy by $5 \%$ of the investment costs, this would lead to an additional $\mathrm{CO}_{2}$ reduction potential of about 230kton (cumulated until 2020). High promotion scheme efficiency could be achieved by raising subsidy for district heating which would result to a higher rate of connected buildings to the existing district heating grid (not assuming a stronger extension of the grid). The according promotion scheme efficiency results to $56 \mathrm{~kg} / €$.

\section{- $\underline{\text { Raising subsidy for biomass heating systems: }}$}

Currently, in Vienna subsidies for small scale biomass heating systems are implemented but their uptake is relatively small and no strong development of biomass systems could be mentioned in the past ${ }^{15}$. So, an increase of biomass subsidies was investigated. It turns out that raising biomass subsidy by $5 \%$ of the investment costs would result in high a promotion scheme efficiency of $84 \mathrm{~kg} / €$. The crucial question for the actual $\mathrm{CO}_{2}$ reduction potential that could be achieved is the question of acceptability and fuel transport. However, due to this high level of promotion scheme efficiency, biomass should be considered as relevant option in the outskirts of Vienna.

\section{- Raising subsidy for solar thermal domestic hot water systems:}

Currently, in Vienna there are investment subsidies for solar thermal domestic hot water systems in the amount of $30 \%$ of the investment costs. The development in the last decade shows that the impact of these subsidies are quite low and the number of installation is far below what would be the technical potential.

Therefore, we investigated the impact of an increase to $50 \%$ investment subsidy. The result is that the total impact still is rather low at a level of 50\% subsidy: In the maximum about 1,900 dwellings per year are supplied by solar thermal systems. Total transfer costs are less than 300,000 Euro per year, $\mathrm{CO}_{2}$ reduction is in the maximum about 500 tonCO $\mathrm{C}_{2} /$ year. This results in a promotion scheme efficiency (CPSE) of about $5.6 \mathrm{~kg} \mathrm{CO}_{2} / €$ in the year 2020 .

\footnotetext{
${ }^{15}$ Due to high soft barriers resulting from comfort issues.
} 
However, the technical potential for $\mathrm{CO}_{2}$ reduction by solar thermal collectors is much higher: Until 2020 over $100 \mathrm{ktonCO} / 2 / \mathrm{yr}$ could be reduced. For achieving this potential quite high level of subsidies (more than 75\%) would be necessary to ensure economic attractiveness.

However, this is true for the assumed moderate price increase for fossil fuels of $1 \%$ per year. The sensitivity analyses carried out with respect to the energy price increase shows that without any increase of the subsidy, a fossil price increase of $4 \%$ per year would lead to a strong boost of solar thermal systems beginning in the year 2015 .

\section{- Extending subsidy for gas condensing boilers:}

The subsidy for gas condensing boilers existing currently in Vienna is restricted to those areas with no availability of district heating. Thus, it is not possible to obtain grants for gas condensing systems if you could connect to district heating. This refers to the strong commitment of Vienna's energy policy promoting the use of district heating.

Thus, we investigated whether there could be a positive impact of extending the subsidy to the whole area of Vienna.

This measure leads to a higher penetration of gas condensing boilers. 510GWh of heat are provided by gas condensing boilers in 2020 compared to $410 \mathrm{GWh}$ in the reference scenario.

However, the impact on $\mathrm{CO}_{2}$ emissions is dubious. In the first years (until 2007) gas condensing boilers primarily replace conventional gas systems (compared with the reference scenario). This leads to a reduction of about $2 \mathrm{ktons} \mathrm{CO}_{2}$ per year in 2007. In the following years (2007-2011) gas condensing boilers primarily replace district heating (compared to the reference scenario). Since the district heating in Vienna stems primarily form waste incineration and gas CHP, the related specific $\mathrm{CO}_{2}$ emission factor is lower than from gas condensing systems. This leads to an increase of annual $\mathrm{CO}_{2}$ emissions of nearly $4 \mathrm{ktons} / \mathrm{yr}$ in 2011. The impact in the last period (2011-2020) is quite low, which is similar to the reference scenario: Natural gas systems are getting less attractive.

\subsubsection{Synopsis}

With the currently in Vienna implemented promotion scheme mix (= reference scenario) 3.1Mton- $\mathrm{CO}_{2 \text { cumulated }}$ compared to a scenario without any promotion schemes can be reduced till 2020. This reduction is basically based on the fact that inefficient heating systems switch to gas and district hating systems. Furthermore, the current Thewosan program turns out to be quite effective and contributes also to this reduction in $\mathrm{CO}_{2}$ emissions. 
However, if we want to reduce the $\mathrm{CO}_{2}$ emissions further we have to increase the existing promotion schemes or have to use a different mix of schemes than in the reference scenario. In other words 'Which promotion scheme mix will be the best to reduce $x \% \mathrm{CO}_{2}$ emissions additionally compared to the current reference scenario?' This question will be answered by the Efficiency $-\mathrm{CO}_{2}$ graph as shown in Figure 4.5.

The point left in the y-axis indicates the currently implemented promotion scheme mix (= reference scenario) in Vienna. Starting at this point the subsidy values for a certain set of strategies are changed resulting to different PSE values. The first simulation point of an efficiency $-\mathrm{CO}_{2}$ graph always indicates no additional DSM subsidy and shows therefore the PSE for additional district heating and/or biomass subsidy only.

However, for the additional reduction of $\mathrm{CO}_{2}$ emissions in the building sector till 2020 different options (increased district heating subsidy, increased DSM subsidy, and increased biomass subsidy) are available. The most efficient measures are the promotion of biomass and district heating which constitute the envelope (highest PSE) in Figure 4.5.
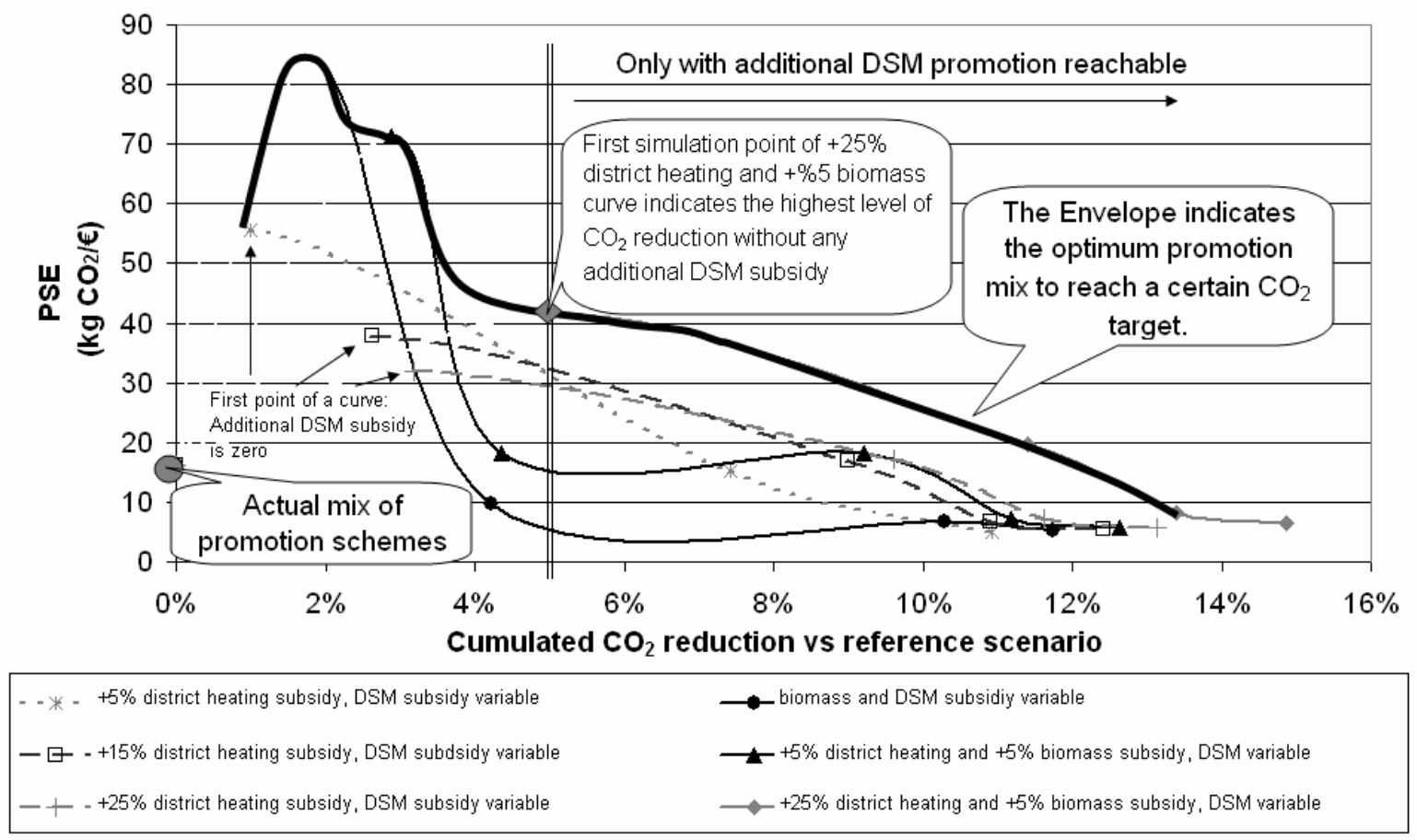

Figure 4.5: Promotion Scheme Efficiency and according $\mathrm{CO}_{2}$ reduction potential in the heating sector for different promotion schemes in Vienna.

As a result of the quite ambitious Thewosan program additional DSM measures are not very efficient. However, DSM measures are indicated by the highest $\mathrm{CO}_{2}$ reduction potential and due to this fact demand side measures have to be considered in Vienna to reach higher additional $\mathrm{CO}_{2}$ reduction goals. 
So, from Figure 4.5 we can learn that the optimum promotion scheme mix depends strongly on the desired additional $\mathrm{CO}_{2}$ reduction goal. A low additional $\mathrm{CO}_{2}$ reduction $(<5 \%)$ can be efficiently achieved with higher biomass as well as district heating subsidies. If additional $\mathrm{CO}_{2}$ reductions above 5\% are favoured it is absolutely necessary to consider higher DSM promotion schemes for the buildings which are indicated by low PSE values.

\section{Policy Lessons Learned}

The investigations of the simulations performed show that $\mathrm{CO}_{2}$-taxes ${ }^{16}$ would represent a very effective instrument. Due to the direct internalization of external costs, inefficiencies with respect to subsidy schemes can be reduced. Of course, the concept of promotion scheme efficiency in terms of saved $\mathrm{CO}_{2}$ emissions per public expenses (PSE) as it has been applied in this paper is not applicable here. The impacts on the economy rather have to be investigated by macroeconomic models. As far as $\mathrm{CO}_{2}$ taxes realized in a manner neutral to the total public budget, their realization is more a matter of political volition and power. In fact, energy taxations in political reality are not always easy to realize.

As long as $\mathrm{CO}_{2}$ taxes or other forms of energy carrier taxes are not implemented in a level high enough fostering RES \& RUE technologies, other incentives have to be set if the ambitious targets shall be achieved. The analyses within Invert as well as other projects have not shown any clear priority for a certain type of instrument like soft loans, subsidies or feedin-tariffs. Rather it is a matter of the right design of each instrument.

One of the core lesson learned is that for a comprehensive analysis and optimization of policy instruments two aspects have to be considered: efficiency and effectiveness. The efficiency of a promotion scheme indicates how much of a target (e.g. $\mathrm{CO}_{2}$-reduction) can be achieved by using a certain amount of public money in terms of $\mathrm{kgCO}_{2} / €$. The effectiveness measures how much this instrument can contribute to reaching a certain target in absolute terms (e.g. $\mathrm{kg} \mathrm{CO}_{2}$ reduction). Both aspects have to be considered at the same time. Considerations of only one aspect may result to fallacy.

\section{Conclusions}

Optimizations neglecting social constraints as education or preferences (e.g. comfort issues) result to the problem that the calculated optimum is not easy to achieve. An optimization algorithm is capable to identify the best optimum, but does not easily reveal how to reach this

\footnotetext{
${ }^{16}$ Or taxes on the consumption of various energy carriers.
} 
optimum. Which political decisions are necessary to reach such an optimum? Is it possible to gain another optimum changing the social constraints? What are the effects of changing the social constraints by introducing information campaigns? All these questions can be answered by a simulation tool, which simulates a certain selected strategy and their impact on future technology deployment as well energy consumption and $\mathrm{CO}_{2}$ emissions.

Invert is not capable to identify the best optimum solution, but it allows finding a way to introduce a certain strategy (e.g. $\mathrm{CO}_{2}$ reduction goal) and to understand where the problems are.

The simulation runs in the seven different European regions have shown that the efficiency according $\mathrm{CO}_{2}$ reduction - of the spent public money strongly depend on the already achieved efficiency potential in the region. In particular, the Promotion Scheme Efficiency (PSE) for Demand-Side-measures is very low in Austria due to the already high building efficiency compared to other countries.

For Vienna the most efficient promotion schemes are biomass and district heating related schemes. However, these schemes do not result to the highest $\mathrm{CO}_{2}$ reduction potential (potentials are restricted) and therefore for more ambitious goals the consideration of DSM measures is compulsory.

One of the most important conclusion derived from the simulation runs is that the optimum promotion mix depends on the desired $\mathrm{CO}_{2}$ reduction and is not fixed for the entire possible range of $\mathrm{CO}_{2}$ reductions. The policy makers have to know the exact $\mathrm{CO}_{2}$ reduction goal and have to fix them to constitute also the best promotion scheme mix. Low reductions in the $\mathrm{CO}_{2}$ emissions $(<5 \%$, for Vienna) can be easily and efficient achieved by increasing the biomass and/or district heating subsidy without any change in the DSM subsidy. More ambitious goals $(>5 \%$, for Vienna) have also to consider increased Demand-Side subsidies which will boost the spent public money due to the already high building efficiency.

\section{Acknowledgment}

This work was performed in the frame of the European project Invert 'Investing in RES and RUE Technologies: Models for Saving Public Money' and was supported by the European Commission, DG TREN under the Altener programme (for the promotion of increased use of renewable energy sources in the European Community 2002) ${ }^{17}$.

\footnotetext{
${ }^{17}$ For more information please take a look at www.Invert.at
} 
In course of this project the Invert simulation tool was designed by the Energy Economics Group and we want to thank all other project partners involved in this project, especially the:

- AGH University of Science and Technology, Poland

- Association for the Conservation of Energy, United Kingdom

- Centro de Estudos em Economia da Energia, dos Transportes e do Ambiente, Portugal

- Demokritos University of Thrace, Greece

- Fraunhofer Institute for Systems and Innovation Research, Germany

- Risoe National Laboratory, Denmark

- Polish Foundation for Energy Efficiency, Poland.

\section{References}

Green-X project (2002 - 2004): „Deriving optimal promotion strategies for increasing the share of RES-E in a dynamic European electricity market", Fifth Framework Programme of the European Commission, website www.green-X.at.

HAAS R., H. Auer, P. Biermayr (1997): “The impact of consumer behaviour on residential energy demand for space heating”. Energy and Buildings 27 (1998) pp 195-205, Vienna 1997.

JOERGENSEN K., L. Kranzl, E. TSIOLIARIDOU, M.-A. Lopez-Polo, M. Stadler, G. Resch, and R. Haas (2004): ,,Rational Use of Energy and Renewable Energy Sources - A Review of current Policy Strategies and Promotion Schemes, Work Package 1 of INVERT" a research project within the ALTENER Program of the European Commission, DG TREN N: 4.1030/Z/02-094, February 2004.

KRANZL L., C. Huber, G. Resch, E. Schriefl, E. Tsioliaridou, E. Negro, M. Ragwitz, and C. LAIA (2004): ,Technology Evaluation, Work Package 2 of Invert” a research project within the ALTENER Program of the European Commission, DG TREN N ${ }^{0}$ : 4.1030/Z/02-094, March 2004.

KRANZL L., M. Stadler, C. Huber, R. Haas, M. Ragwitz (2005): „Comparing policy options: Methodology and conclusions derived from Invert “. International dissemination conference of the project Invert in Brussels, Belgium, April $21^{\text {st }} 2005$.

KRATENA K., S. Schleicher (2001): „Energieszenarien bis 2020“. By order of the Austrian Federal Ministry of Economic Concerns and Federal Ministry of Agriculture and Environment Concerns. - Vienna 2001.

RAGWITZ M., A. Brakhage, L. Kranzl, M. Stadler, C. Huber, R. Haas, E. Tsiolaridou, J. Pett, P. Gürtler, K. Joergensen, A. Figorski, A. Gula, E. Gula, B. SLIZ, and A. Wyrma (2005): ,C Case Studies, Work Package 6 of Invert” a research project within the ALTENER Program of the European Commission, DG TREN N ${ }^{\circ}: 4.1030 / Z / 02-$ 094, February 2005. 
RAGWITZ M., Huber C., G. Resch, S. White (2003): „Deriving Optimal Promotion Strategies for Increasing the Share of RES-E in a dynamic European Electricity Market, Working paper of WP1 - Dynamic cost resources curves", Green-X a research project within the $5^{\text {th }}$ framework programme of the European Commission, DG Research, August 2003.

RESCH G., T. Faber, R. Haas, C. Huber (2004): "Experience curves vs dynamic costresource curves and their impact on the assessment of the future development of renewables”, Energy \& Environment, Volume 15, Issue 2, p. 116-126, 2004

STADLER M., L. Kranzl, G. Resch, C. Huber, R. Haas (2005): „Invert Simulation Tool: Modelling Promotion Schemes for sustainable energy systems". International dissemination conference of the project Invert in Brussels, Belgium, April $21^{\text {st }} 2005$.

STADLER M., L. Kranzl, G. Resch, C. Huber, R. Haas (2005): „Introduction to the Invert Simulation Tool". International dissemination conference of the project Invert in Brussels, Belgium, April $21^{\text {st }} 2005$.

STADLER M., L. Kranzl, and C. Huber (2004): ,, The INVERT Simulation Tool, User Manual - Version 1.0.0, Working Paper of Phase 5 of the project Invert" a research project within the ALTENER Program of the European Commission, DG TREN Contract $\mathrm{N}^{0}:$ 4.1030/Z/02-094, September 2004. 